\title{
ВЫЖИГАНИЕ ПРОВАЛА В НЕОДНОРОДНО УШИРЕННЫХ СПЕКТРАХ ПОЛИМЕТИНОВЫХ И ОКСАЗИНОВЫХ КРАСИТЕЛЕЙ В НИЗКОТЕМПЕРАТУРНЫХ МАТРИЦАХ
}

\author{
(Представил К. К. Ребане)
}

Со времени своего обнаружения фотоиндуцированное выжигание провала в неоднородно уширенных спектрах замороженных растворов больших органических молекул при гелиевых температурах $\left[{ }^{1,2}\right]$ превратилось в многообещающий метод детального изучения характеристик однородных примесных спектров.

В настоящее время выжигание провала позволяет следить за такими интересными явлениями, как процессы релаксации, малые сдвиги и расщепления частот переходов в примесных центрах и другие, а также за собственно механизмами фотохимических превращений в низкотемпературных молекулярных системах, ответственных за деформацию неоднородного распределения $\left[{ }^{3}\right]$. Некоторые результаты в исследовании таких важных биологических молекул, как хлорофилл и его аналоги также обязаны применению метода выжигания провала $\left[{ }^{4,5}\right]$.

Эффект выжигания провала примечателен и в прикладном отношении, так как дает принципиальную возможность создания оптических элементов памяти повышенной плотности записи информации за счет привлечения дополнительной координаты записи информации - длины волны в пределах неоднородной полосы $\left[{ }^{6,7}\right]$.

В данной работе исследовалось более подробно отмеченное в $\left[{ }^{7}\right]$ выжигание узких провалов в спектрах растворов полиметиновых и оксазиновых красителей. Классы этих соединений имеют большое прикладное значение в качестве активных (и пассивных) сред в лазерной технике и поэтому получение детальной спектроскопической информации о них актуально.

\section{Эксперимент}

Провал в неоднородно уширенном спектре поглощения растворов красителей при гелиевых температурах выжигался лазером на оксазине 1. За выжиганием провалов наблюдали путем измерения спектров возбуждения люминесценции, снятых при помощи монохроматоров ДФС- ?4 и МДР-4, "имеющих аппаратные функции 0,3 и $3 \mathrm{~cm}^{-1}$ соответственно. Источником возбуждения служила лампа накаливания. Люминесценцию красителей проявляли фильтрами ФС-7 и регистрировали посредством системы счета фотонов.

Растворы красителей приготовляли в кварцевых кюветах толщиной 1 мм, а полиметилметакрилатные пленки с примесью красителей - на стеклянных подложках, и при 20-50\%-ном оптическом пропускании они были толщиной примерно 50 мкм. Объекты погружали в гелиевый криостат с регулируемой температурой. 
Первые данные о наличии узких бесфононных линий $\left[{ }^{8}\right]$ в низкотемпературных растворах полиметиновых и оксазиновых красителей были получены в экспериментах с двухступенчатым возбуждением флуоресценции в растворах полиметинового красителя криптоцианина при $4,2 \mathrm{~K}$ $\left[{ }^{9}\right]$.

В кинетике гашения сигнала двухступенчато возбужденной флуоресценции по мере длительности возбуждения можно было выделить два компонента скорости. Это можно объяснить, если предположить, что имело место фотохимическое выжигание провала в спектре поглощения, причем оно осуществлялось как через бесфононные линии, так и через фононные крылья.

Сделанное предположение нашло подтверждение в квазилинейчатой структуре спектров люминесценции [ $\left.{ }^{9}\right]$, полученных при монохроматическом возбуждении лазером на оксазине 1 . Вид квазилинейчатого спектра зависит как от длины волны возбуждения (рис. 1), так и от продолжительности облучения. Последний факт в свою очередь свидетельствует о наличии в неоднородном ансамбле молекул фотонндуцированных превращений, которые делают возможным выжигание провала $\left[{ }^{1-3}\right]$.

В прямых исследованиях методом выжигания провала ряда замороженных растворов полиметиновых и оксазиновых красителей, проведенных в рамках данной работы, прекрасно проявляется характерная кинетика процесса выжигания. Пронллюстрируем это конкретным примером с раствором криптоцианина в спирте при $4,2 \mathrm{~K}$.

1. При малых экспозициях выжигания в спектре возбуждения появляется узкий ненасыщенный провал [ $\left.{ }^{3}\right]$, связанный с поглощением выжигающего излучения в бесфононных линиях молекул красителя (рис. 2,6$)$ : отсутствие фононного крыла на этой стадии выжигания указывает на значительную в данных условиях величину фактора Дебая-Валлера.

2. При увеличении времени экспозиции выжигание выявляется через фононное крыло $\left[{ }^{3}\right]$ (рис. $2, б$ ) и обнаруживается также сдвинутый на $170 \mathrm{~cm}^{-1}$ провал, соответствующий уменьшению поглощения в $0-0$ линиях набора тех молекул, колебательное повторение 0-0 перехода которых оказалось в резонансе с выжигающим лазером.

3. Еще более длительная экспозиция (в данном случае мощностью $50 \mathrm{mBT} / \mathrm{cm}^{2}$ в течение нескольких минут) приводит к почти полному выжиганию центров с длинноволновой (относительно возбуждения) стороны неоднородной полосы и к образованию нового стационарного неоднородного распределения в коротковолновой области полосы поглощения (рис. 2,a) с заметной структурой в коротковолновой части спектра возбуждения.

Установленное почти полное выгорание центров с длинноволновой стороны от лазерного возбуждения указывает на то, что в данном случае не реализуется предложенный в [ $\left.{ }^{11}\right]$ т. н. нефотохимический механизм выжигания, согласно которому выжигание провала в стеклообразующих матрицах происходит благодаря фотоиндуцированным переходам между двумя туннельными состояниями окружающей примесь матрицы. Как показано в $\left[{ }^{12}\right]$, для объяснения столь глубокого выжигания длинноволновой части полосы поглощения необходимо сделать предположение о наличии многих возможных равновесных кон-

* О наблюдении квазилинейчатой структуры в спектрах люминесценции растворов полиметиновых красителей при $4,2 \mathrm{~K}$ сообщалось независимо авторами работы [10]. 


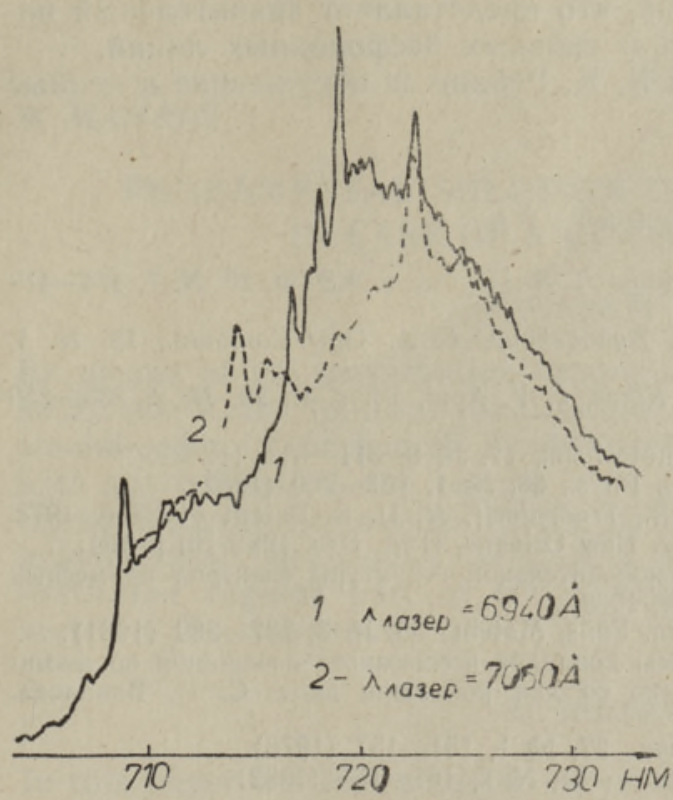

Рис: 1. Структурный спектр люминесценции криптоцианина в матрице спирта при 4,2 К в условиях монохроматического возбуждения.

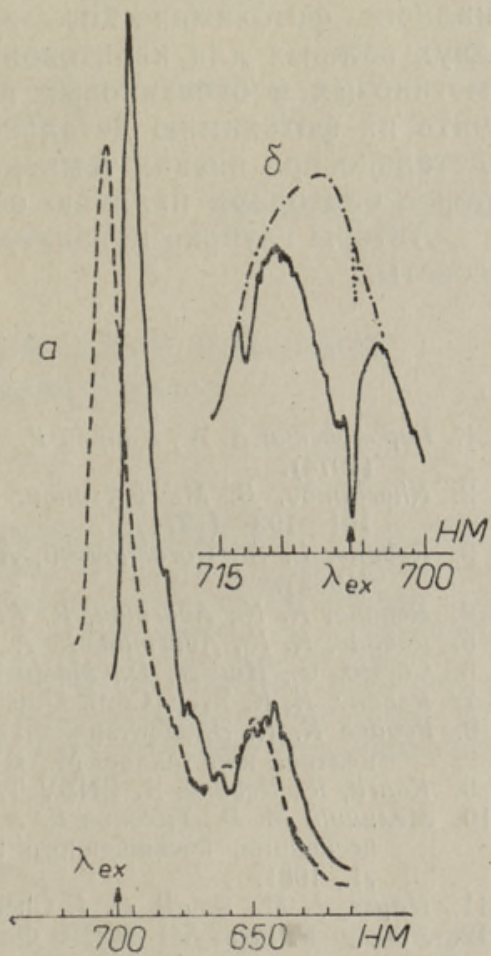

Рис. 2. Провалы в спектре возбуждения криптоцианина в матрице спирта при 4,2 K. $a$ - начальное неоднородное распределение полосы (I) и распределение после длительного выжигания $(2), \sigma-$ эволюция провала при сравнительно малых экспозициях.

фигураций примеси в матрице (между которыми возможны фотоиндуцированные переходы) с разными частотами бесфононного перехода.

Исследование молекул криптоцианина и оксазина 750 в качестве примесей в пленках полиметилметакрилата выявило нескольжо различный характер взаимодействия этих примесей с матрицей нежели тех же молекул в рассмотренных выше матрицах спирта и других полярных растворителей. Значительное увеличение времени экспозиции (на 23 порядка) при выжигании провалов, относительно малая глубина насыщенного провала в этих системах (не более 10\%), а также отсутствие квазилинейчатой структуры в селективно возбужденных спектрах люминесценции указывают, с одной стороны, на малое значение фактора Дебая-Валлера, а с другой, на принципиально иной характер механизма выжигания провала в данных системах. Учитывая малую полярность полиметилметакрилата, такое поведение исследуемых красителей в данной пленке может быть связано и с образованием димеров и ассоциатов с анионом примеси.

Исходя из опыта с примесными пленками, следует обратить внимание на то, что методом выжигания провала благодаря своего рода накоплению сигнала можно было детектировать и сравнительно слабые бесфононные линии, которые в спектре люминесценции при монохроматическом возбуждении не проявились достаточно четко.

В заключение можно отметить, что в данной работе установлено 
наличие фотохимического выжигания провала в растворах молекул двух важных для квантовой электроники классов соединений - полиметиновых и оксазиновых красителей. Это позволяет, во-первых, изучить их фотохимию детально, во-вторых, изучить однородные спектры детально при низких температурах, что представляет значительный интерес благодаря наличию острых и сильных бесфононных линий.

Авторы глубоко признательны К. К. Ребане за обсуждение и ценные советы.

\section{ЛИ Т ЕРА Т Р А}

1. Гороховский А. А., Каарли Р. К., Ребане Л. А. Письма в ЖЭТФ, 20, № 7, 474-479 (1974).

2. Kharlamov, B. M., Personov, R. I., Bykovskaya, L. A. Opt. Commun., 12, № 1, 191-193 (1974).

3. Rebane, L. A., Gorokhovskii, A. A., Kikas, J. V. Appl. Phys. B, 29, № 2, 235-250 (1982).

4. Rebane, K. K., Avarmaa, R. A. J. Photochem., 17, № 8, 311-317 (1982).

5. Rebane, K. K., Avarmaa, R. A. Chem. Phys., 68, № 1, 191-200 (1982).

6. Castro, G., Haarer, D., Macfarlane, R., Tromsdorff, H. U. S. Patent 4103346, 1978.

7. Rebane, K. K. Proc. Conf. «Lasers-82». New Orleans, USA, Dec. 1982 (in print).

8. Ребане K. K. Элементарная теория колебательной структуры спектров примесных центров кристаллов. М., «Наука», 1968.

9. Kaarli, R., Rebane, A. ENSV TA Toim. Füüs. Matem., 30, № 3, 287-289 (1981).

10. Мелищук M. В., Тихонов E. А. Тезисы докладов всесоюзного совещания по люминесценции, посвященного 90-летию со дня рождения акад. С. И. Вавилова. Л., 1981.

11. Hayes, J. M., Small, G. J. Chem. Phys., 27, № 1, 151-157 (1978).

12. Яанисо Р. Изв. АН ЭССР, Физ. Матем., 31, № 2, 161-165 (1982).
Институт физики
Академии наук Эстонской ССР Поступила в редакцию
$7 / \mathrm{IV}$
1983

R. KAARLI, A. REBANE, P. SAARI

\section{AUGU POLLTAMINE POLUMETUUN- JA OKSASIINVÄRVAINETE MITTEHOMOGEENSELT LAIENENUD SPEKTRITES MADALATEMPERATUURILISTES MAATRIKSITES}

Artikkel käsitleb augu põletamist kahe kvantelektroonikas tähtsa ühenditeklassi polümetüün- ja oksasinvärvainete korral ning mõningate polümetüün- ja oksasiinvärvainete lahuseid vedela heeliumi temperatuuril. On kindlaks' tehtud kitsaste foononivabade joonte ja neid saatvate foonontibade olemasolu nende süsteemide spektrites. Augu pōletamise protsessi on uuritud eri tüüpi maatriksites.

R. KAARLI, A. REBANE, P. SAARI

\section{HOLE BURNING OF INHOMOGENEOUS SPECTRA OF POLYMETHYNE AND OXAZINE DYES IN LOW TEMPERATURE MATRICES}

Spectral hole burning is established for two classes of important compounds in quantum electronics - polymethyne and oxazine dyes. By this method we have studied some polymethyne and oxazine dye solutions in ethanol and polymethyne metacrylate at liquid helium temperatures. The existence of narrow zero phonon lines accompanied by phononwings is established in these systems, and the burning process in different types of matrices is investigated. 